IIIIIIIIIIIIIIIIIIIIIIIIIIIIIIIIIIII

Original Article

IIIIIIIIIIIIIIIIIIIIIIIIIIIIIIIIIIIII

\title{
Effect of a novel repellent, acetylated glyceride, against sweet potato whitefly, Bemisia tabaci (Gennadius) (Hemiptera: Aleyrodidae)
}

\author{
Takayuki Kashima, ${ }^{1,3, *}$ Chiaki TakedA, ${ }^{1}$ Nobuyuki AkıYoshi, ${ }^{2}$ \\ Kiyomitsu Yoshida ${ }^{1}$ and Yutaka ARImoto ${ }^{3}$ \\ ${ }^{1}$ Central Research Institute, Ishihara Sangyo Kaisha, Ltd., 2-3-1 Nishi-Shibukawa, Kusatsu, Shiga 525-0025, Japan \\ ${ }^{2}$ Market and Development department, Ishihara Sangyo Kaisha, Ltd., 1-3-15 Edobori, Nishi-ku, Osaka, Osaka 550-0002, Japan \\ ${ }^{3}$ Inovation Center, Riken Institute, 2-1 Hirosawa, Wako, Saitama 351-0198, Japan
}

(Received November 18, 2013; Accepted March 10, 2014)

\begin{abstract}
With the aim of identifying safe control agents for whiteflies, we screened foods and food additives and observed that acetylated glyceride showed strong repellent activity against the sweet potato whitefly Bemisia tabaci. The acetylated glyceride (acetic and fatty acid esters of glycerol) has been used as food additives worldwide. The numbers of settled adults, courting pairs, and nymphs on host plant leaves were reduced by acetylated glyceride treatment. The highest control was attained with foliar treatment $(0.2 \%, \mathrm{v} / \mathrm{v})$ at 7 -day intervals. Phytotoxicity to tomato plants was below the commercially acceptable level. The acetylated glyceride was harmless against four species of natural enemies examined. () Pesticide Science Society of Japan

Keywords: acetylated glyceride, Bemisia tabaci, food additive, courting pair, natural enemy, repellent.

Electronic supplementary materials: The online version of this article contains supplementary materials (Supplemental Tables S1-S3), which are available at http://www.jstage.jst.go.jp/browse/jpestics/.
\end{abstract}

\section{Introduction}

The sweet potato whitefly Bemisia tabaci (Gennadius) is one of the most destructive insect pests of vegetables and ornamental plants in the tropics and subtropics. ${ }^{1,2)}$ Its host range is very broad and covers approximately 600 plant species, including several economically important vegetable crops. ${ }^{3)}$ Plant damage is caused directly by feeding on phloem sap and indirectly by excreted honeydew, which saprophytic fungi use as a nutrient source, damaging foliage and fruits. In addition, the insect transmits 128 plant viruses. ${ }^{4)}$ Annually, whiteflies cause extensive economic loss. For instance, in Brazil, almost all vegetable fields are seriously damaged by $B$. tabaci, incurring a cumulative economic loss of US $\$ 5$ billion or greater since 1995. . $^{\text {) }}$

The Q-biotype of B. tabaci is believed to have originated in the Iberian peninsula ${ }^{6)}$ and is now distributed in Japan, ${ }^{7)}$ China, ${ }^{8,9)}$ the USA, ${ }^{10)}$ and several other areas, with the exception of Antarctica. ${ }^{11)}$ This biotype not only is highly resistant to several kinds of insecticides ${ }^{12)}$ but also exhibits cross-resistance to insecticides such as chloronicotinyl, ${ }^{13)}$ which plays a pivotal role in control programs for important insect pests.

Several attempts have been made to develop effective control

\footnotetext{
* To whom correspondence should be addressed.

E-mail: t-kashima@iskweb.co.jp

Published online April 27, 2014

(c) Pesticide Science Society of Japan
}

measures for whiteflies. Among these measures, the most widely used are insecticides. However, continuous field application of insecticides is not practical, particularly during the harvest season, as they occasionally harm natural enemies and pollinators and deposit pesticide residues on crops.

As an alternative to pesticides, biological control has been extensively studied using various natural enemies. However, it is not easily applicable in fields, partly because growers are required to have deep technical knowledge of the economic injury level (EIL) and economic threshold (ET), which are essential for efficiently deploying natural enemies.

The effect of plant extracts and vegetable oils as repellents, antifeedants, and toxicants has been evaluated against whiteflies $B$. tabaci ${ }^{14-24)}$ and Trialeurodes vaporariorum. ${ }^{25-28)}$ However, commercially applicable and environmentally safe substances are very limited in number, and some demonstrate insufficient performance and occasional incidents of phytotoxicity. ${ }^{16,17,21)}$

We conducted a thorough screening of food and food additives that have been scientifically proven to be safe and whose safety is also empirically supported by a long history of dietary intake based on our concept of Safe and Friendly to the Environment (SaFE). After extensive screening tests, we observed that acetylated glyceride (acetic and fatty acid esters of glycerol), as a food additive, exhibited strong repellent activity against $B$. tabaci adults without causing phytotoxicity to vegetable crops or toxicity to beneficial insects.

In this report, we describe the effect of acetylated glyceride on 
the numbers of settled adults, courting pairs, and nymphs of the sweet potato whitefly on host plant leaves, along with its phytotoxicity and side effects on natural enemies.

\section{Materials and Methods}

\section{Insects tested}

The B-biotype of the sweet potato whitefly B. tabaci was used as the test insect. The whitefly was reared on potted cabbage plants in growth chambers at $25^{\circ} \mathrm{C}$ at approximately $70 \% \mathrm{RH}$ under a 16:8 hr light: dark cycle. Under these rearing conditions, the development time from egg to adult was $23 \pm 1$ days.

\section{Acetylated glyceride}

After screening several plant-derived oils and food additives, we observed that acetylated glyceride (Fig. 1) had a strong repellent effect and was formulated as an $80 \%$ emulsifiable concentrate (under the developmental code name IKR-001EC). Phytotoxicity on tomato leaves and fruit was at a commercially acceptable level following treatment with acetylated glyceride $(0.2 \%, \mathrm{v} / \mathrm{v})$ three times at 7-day intervals, while problematic phytotoxicity appeared on a few fruits following treatment at $0.4 \%(\mathrm{v} / \mathrm{v})$ in the greenhouse (Supplemental Table S1). Therefore, the effects of acetylated glyceride on whiteflies and their natural enemies were accordingly evaluated after treatment with a water solution of acetylated glyceride $(0.1,0.125,0.2 \%, \mathrm{v} / \mathrm{v})$. Water was sprayed as a control in all experiments. A treatment with only inert ingredients showed no repellent or courting disruption effects on whiteflies (Supplemental Tables S2 and S3). No spreader was used to prepare the spray.

\section{Repellent effect}

Upon landing on preferred host plants, most adult whiteflies move to and settle on the undersides of leaves, where they feed on phloem sap, rest, grow, and reproduce. Based on this behavior, the repellent effect of acetylated glyceride treatment was evaluated by comparing the number of whiteflies on the undersides of leaves treated and untreated with acetylated glyceride.

3.1. Pot tests in a glass greenhouse

Tomato (cv. Kyouryoku-Beiju) plants were grown in $15-\mathrm{cm}$ plastic pots in a whitefly-free greenhouse at our institute. When seedlings reached true leaf stages 8-9 on August 1, 2007 they were treated with acetylated glyceride $(0.2,0.125$, and $0.1 \%, \mathrm{v} / \mathrm{v})$. Four treated and four untreated potted plants were placed in two

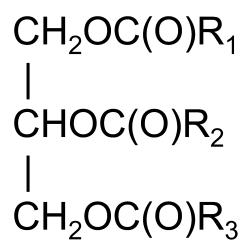

Fig. 1. Chemical structure of the active ingredients (acetylated glyceride $=$ acetic and fatty acid esters of glycerol). $\mathrm{R}_{1}, \mathrm{R}_{2}, \mathrm{R}_{3}=\left(\mathrm{CH}_{2}\right)_{n} \mathrm{CH}_{3}$ $(n=6,8,10,12,14,16)$. One or two of $\mathrm{R}_{1}, \mathrm{R}_{2}$, and $\mathrm{R}_{3}$ are $\mathrm{CH}_{3}$. rows on a greenhouse bench, alternately arranged at equidistant intervals (approximately $50 \mathrm{~cm}$ ). In the middle of the two plant rows, four potted cabbage plants with numerous $B$. tabaci nymphs and adults were placed as an adult migration source. At $1,2,5$, and 7 days after plant placement, the settled adults on all leaves of the treated and untreated tomato plants were counted. The experiment was performed with one replicate.

\subsection{Plastic greenhouse test}

Eggplants (cv. Senryo Ni Gou) at true leaf stages 7-9 with B. tabaci eggs, first instar nymphs, and adults were treated with acetylated glyceride $(0.2 \%, \mathrm{v} / \mathrm{v})$. Seven to nine plants per plot were planted in duplicate. The plants were treated three times at 7-8-day intervals. The test was conducted in a plastic greenhouse $\left(5.5 \times 12 \mathrm{~m}=66 \mathrm{~m}^{2}\right)$ near Kusatsu City from April 4, 2006, to May 8, 2006. Settled adults on 20 randomly selected leaves were counted $2,6,7,9,12,15,19,23$, and 33 days after the first treatment. At 33 days, the third and fourth instar nymphs on leaves were counted as progeny. Unless otherwise indicated, counting included only the third and fourth instar nymphs, easily visible to the naked eye.

\section{Effect on courting}

B. tabaci male adults generally perform courtship, leading to mating on the undersides of host plant leaves. Based on this behavior, the effect of acetylated glyceride treatment on $B$. tabaci courting pair formation was evaluated in the two experiments described below. In these experiments, the courting pairs were counted based on the number of female adults, irrespective of the number of males that paired with a single female; a single female and a single male, as well as a single female and several males were considered as one pair.

Experiment 1: Courting pairs were counted in the greenhouse $1,2,5$, and 7 days after treatment with acetylated glyceride $(0.1 \%, 0.125 \%, 0.2 \%, v / v)$ on tomato leaves (cv. KyouryokuBeiju) at true leaf stages $8-9$ as described in section 3.1. The experiment was performed using four treated and four untreated potted plants, with one replicate.

Experiment 2: As described in section 3.2, courting pairs were counted in the greenhouse $2,6,7,9,12,15,19,23$, and 33 days after the first treatment with acetylated glyceride $(0.2 \%, \mathrm{v} / \mathrm{v})$ on eggplants (cv. Senryo Ni Gou) at true leaf stages 7-9 that were parasitized by eggs, nymphs, and adults. The plants were treated three times at 7-8-day intervals. The experiment was performed in duplicate using 7-9 plants per plot.

\section{Effect on nymphs remaining on leaves}

Two greenhouse experiments were performed to evaluate the effect of acetylated glyceride treatment on the production of B. tabaci progeny. Progeny were counted as nymphs and exuviae. Fourth instar nymphs were discriminated from third instar nymphs by the presence of developing eyespots.

Experiment 1: As described in section 3.2, eggplants (cv. Senryo Ni Gou) with whiteflies at mixed developmental stages were treated with acetylated glyceride $(0.2 \%, \mathrm{v} / \mathrm{v})$, first at true leaf 
stages 7-9 and, subsequently, three times at 7-8-day intervals. Seven to nine plants were used for each plot in duplicate. Thirtythree days after the first treatment, nymphs on 20 randomly selected leaves were counted.

Experiment 2: Grape tomatoes (cv. Yellow Pear) at true leaf stages 9-10 with $B$. tabaci eggs, nymphs, and adults were treated with acetylated glyceride ( 0.2 and $0.125 \%, v / v)$ on August 17, 2007. The plants were treated three times at 7 -day intervals in a plastic greenhouse $\left(5.5 \times 12 \mathrm{~m}=66 \mathrm{~m}^{2}\right)$ near Kusatsu City. Five plants per treatment were planted in duplicate. Twenty-three days after the first treatment, nymphs and exuviae on all leaves were counted as progeny.

\section{Mortality of natural enemies}

With the aim of evaluating the side effects of acetylated glyceride treatment, mortality was evaluated with three replicates for different developmental stages of natural enemies of whiteflies 5-15 days after direct and/or contact treatment with acetylated glyceride $(0.2 \%, v / v)$. The four species of natural enemies examined are all commercially available products from the Arysta LifeScience Corporation: the predacious mite Phytoseiulus persimilis (SPIDEX $\left.{ }^{\circledR}\right)$, the predacious mite Amblyseius californicus $\left(\right.$ SPICAL EX ${ }^{\circledR}$ ), the predatory bug Orius strigicollis (TAIRIKU ${ }^{\circledR}$ ), and the parasitoid Encarsia formosa (EN-STRIP $\left.{ }^{\circledR}\right)$.

Mortality was corrected before analysis using Abbott's formula: $\%$ corrected mortality $=(\%$ mortality in treated $-\%$ mortality in untreated $) /(100-\%$ mortality in untreated $) \times 100$. The corrected mortality was assigned to one of the four classes: class I, harmless (<30\% mortality); class II, slightly harmful (30-79\%); class III, moderately harmful (80-99\%), and class IV, harmful (>99\%), following the toxicity ratings of the International Organization for Biological and Integrated Control of Noxious Animals and Plants (IOBC). ${ }^{29)}$

\section{Data analysis}

One-way ANOVA was employed to assess the effect of acetylated glyceride treatment on the numbers of nymphs and exuviae in the greenhouse experiments. Differences among means were compared with Tukey's honestly significant difference at $p=0.05$.

\section{Results}

\section{Repellent effect}

Figure 2 shows the repellent effect of acetylated glyceride treatment evaluated by the number of $B$. tabaci settled adults on potted tomato plants in the glass greenhouse. In the 7-day timecourse experiment, the number of settled adults on treated tomato leaves remained lower as compared to the number on untreated leaves. One day after treatment with $0.2 \%, 0.125 \%$, and $0.1 \%(\mathrm{v} / \mathrm{v})$ acetylated glyceride, the numbers of settled adults were $85 \%, 82 \%$, and $72 \%$ lower, respectively, compared with the numbers on untreated plants, respectively. Treatment at the highest concentration $(0.2 \%, \mathrm{v} / \mathrm{v})$ tended to show a stable repellent effect on adults compared to treatment with other concentrations for 7 days.

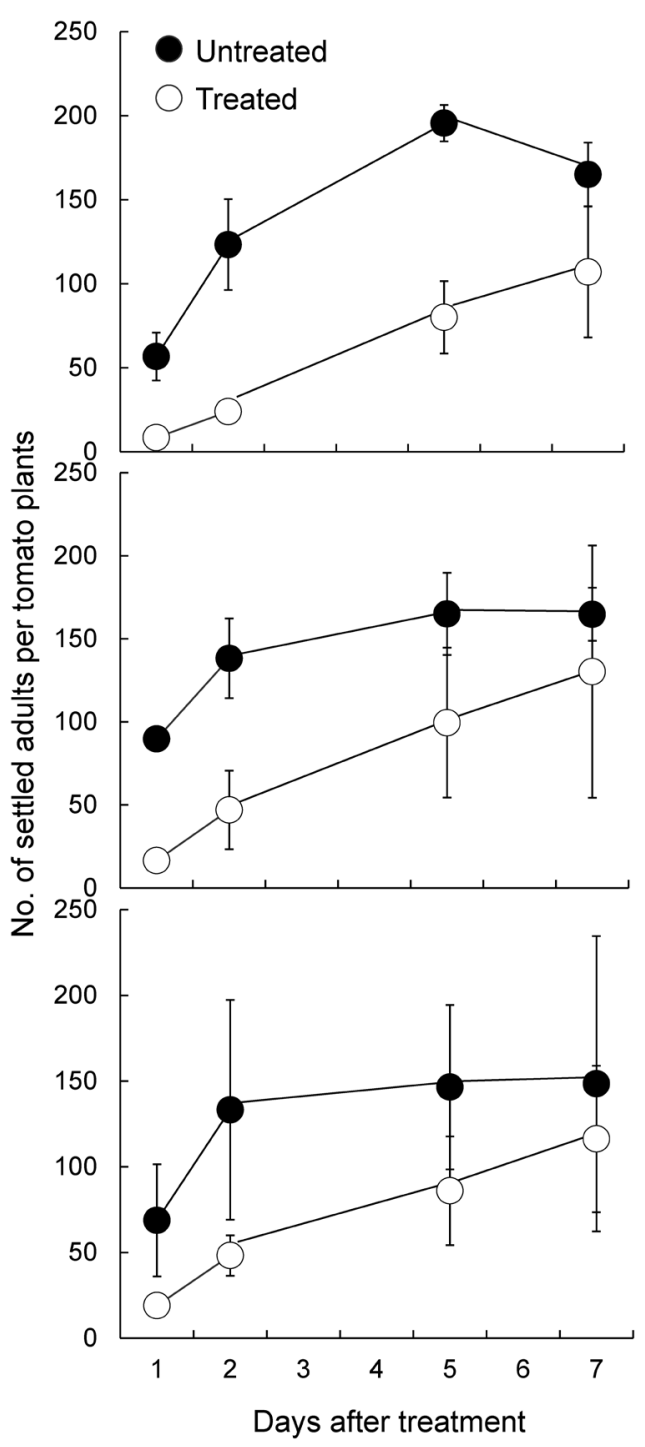

Fig. 2. Effect of acetylated glyceride treatment on the settling of B. tabaci (B-biotype) adults on potted tomato leaves. Each value is the mean \pm standard error (S.E.) of four plants with one replicate.

Figure 3 shows the effect of successive foliar treatment with $0.2 \%(\mathrm{v} / \mathrm{v})$ acetylated glyceride on the settling of whiteflies on eggplant leaves in the plastic greenhouse. On untreated leaves, the number of settled adults increased during the first 6 days and gradually decreased with time. In contrast, whitefly populations on treated leaves remained below approximately $45 \%$ of those on untreated plants. Two days after the second treatment, the number of settled adults per 20 leaves decreased to approximately $84 \%$ per leaf, corresponding to 1.8 per leaf, on average. This low population level persisted until the end of the experimental period, which was 33 days after the first treatment.

\section{Effect on courting}

The effect of acetylated glyceride treatment on B. tabaci courting pair formation on potted tomato plants is shown in Fig. 4. 


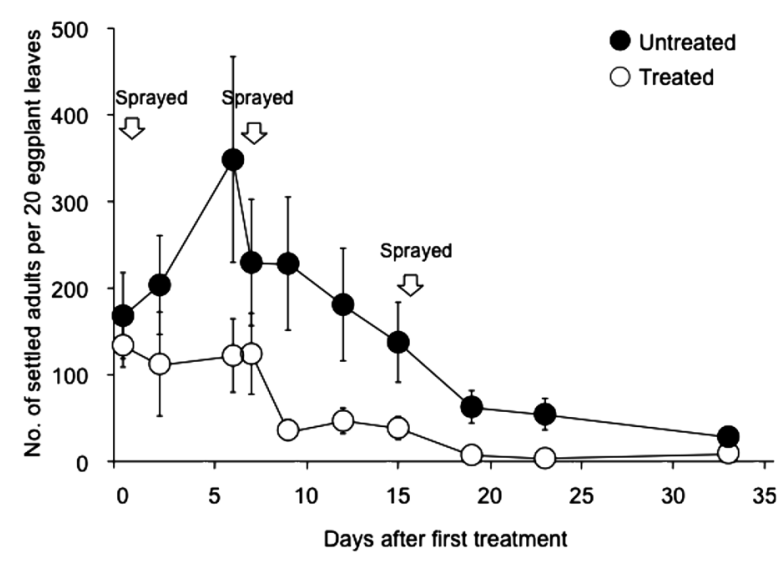

Fig. 3. Effect of acetylated glyceride treatment on the settling of B. tabaci (B-biotype) adults on eggplant leaves. Each value is the mean \pm S.E. of seven to nine plants in duplicates.

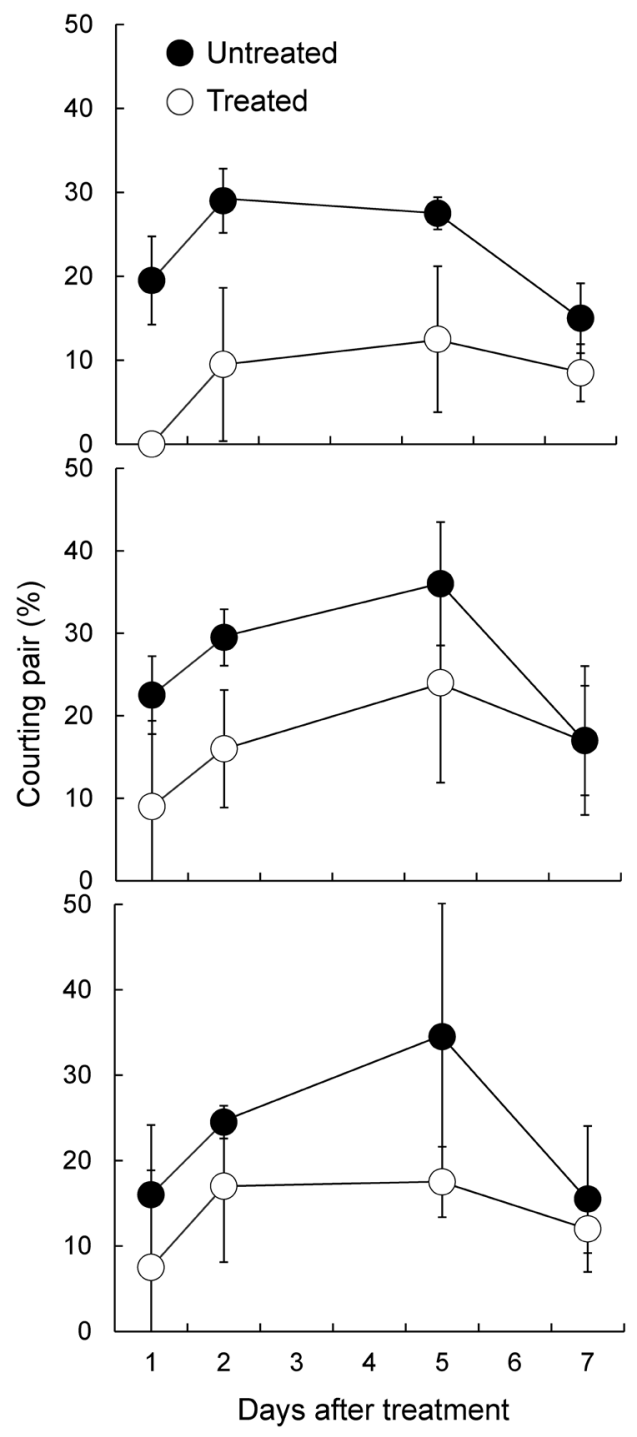

Fig. 4. Effect of acetylated glyceride treatment on B. tabaci (B-biotype) courting on potted tomato plant leaves. Each value is the mean \pm S.E. of four plants with one replicate.

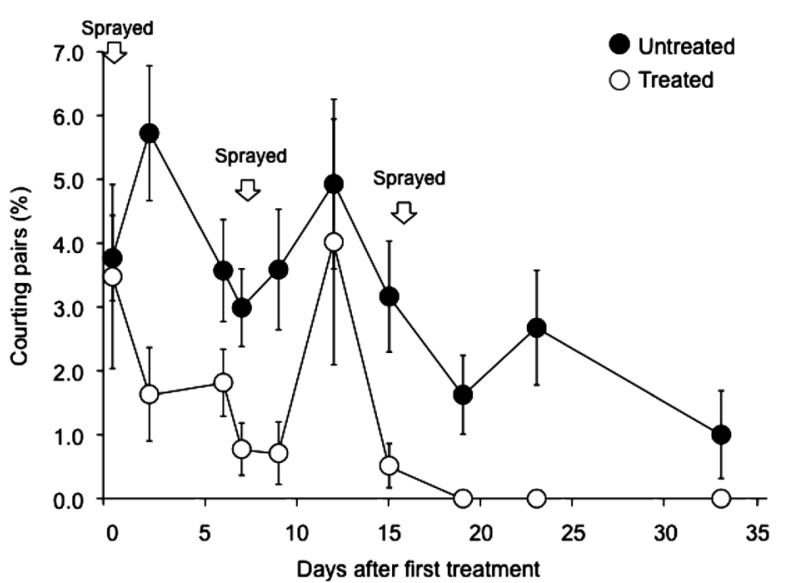

Fig. 5. Effect of acetylated glyceride treatment on B. tabaci (B-biotype) courting on eggplant leaves. Each value is the mean \pm S.E. of seven to nine plants in duplicates.

One day after treatment with $0.2 \%, 0.125 \%$, and $0.1 \%(\mathrm{v} / \mathrm{v})$ of acetylated glyceride, the proportions of adults showing courting behavior were $0 \%$ (20\% for the untreated control), 9\% (23\%), and $8 \%(16 \%)$, respectively. Courting pair formation tended to be more strongly inhibited by acetylated glyceride treatment at the highest concentration $(0.2 \%, \mathrm{v} / \mathrm{v})$; the percentage of courting pairs on the treated leaves was lower than $6-20 \%$ of that on untreated leaves throughout the experimental period of 7 days in the glass greenhouse.

Figure 5 shows the effect of successive treatments of acetylated glyceride on $B$. tabaci courting pair formation on eggplants in the plastic greenhouse. The percentage of courting pairs per settled adult on treated leaves was reduced to $\leq 60 \%$ throughout the test period, except 12 days after the first treatment.

\section{Effect on nymphs remaining on leaves}

Figure 6 shows the effect of acetylated glyceride treatment on the population size of $B$. tabaci nymphs remaining on eggplant leaves. The total numbers of third and fourth instar nymphs were significantly reduced after treatment with acetylated glyceride $(0.2 \%, \mathrm{v} / \mathrm{v})(p<0.05, t$-test $)$. Thirty-three days after treatment, the average numbers of nymphs remaining on treated and untreated leaves were 76 and 744 per 20 leaves, corresponding to 3.8 and 37.2 per leaf, respectively.

As shown in Fig. 7, there was a significant difference in the numbers of third and fourth instar nymphs and exuviae among the treatments $(p<0.05$, Tukey's HSD test). The nymphs and exuviae showed a dose-dependent response to acetylated glyceride treatment; the numbers of nymphs remaining on the grape tomato leaves after treatment with $0.2 \%$ acetylated glyceride, $0.125 \%$ acetylated glyceride, and $0 \%$ (water) were 7,17 , and 82 , respectively. For all treatments, the numbers of remaining exuviae were greater than those of nymphs.

\section{Side effect on natural enemies}

Direct and/or contact treatment with acetylated glyceride $(0.2 \%$, 


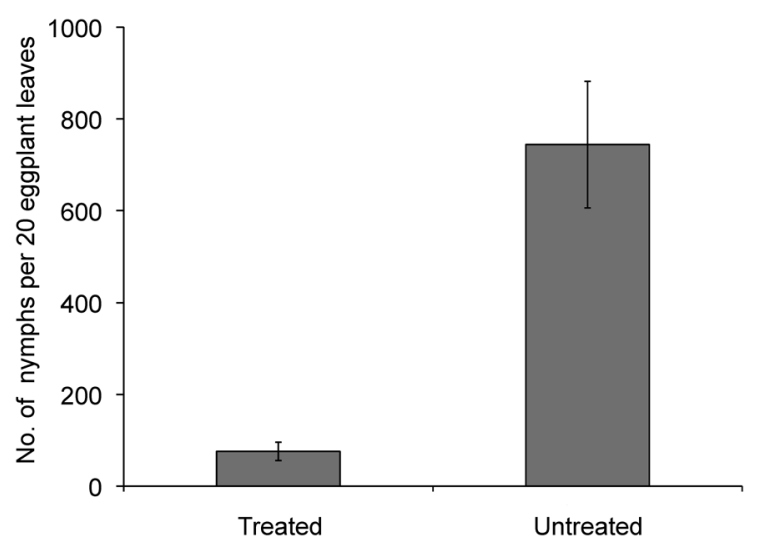

Fig. 6. Effect of acetylated glyceride treatment on the population size of B. tabaci (B-biotype) nymphs remaining on eggplant leaves. Each value is the mean \pm S.E. of seven to nine plants in duplicate.

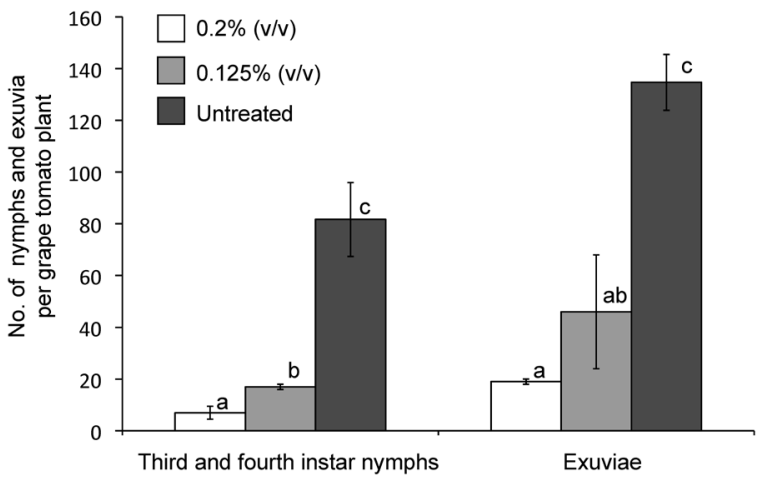

Fig. 7. Effect of acetylated glyceride treatment on the population size of $B$. tabaci (B-biotype) nymphs and exuviae remaining on grape tomato leaves. Each value is the mean \pm S.E. of five plants in duplicate. Different letters indicate significant differences among treatments $(p<0.05$, Tukey's HSD test).

$\mathrm{v} / \mathrm{v})$ did not cause significant mortality at the various developmental stages of the natural enemies examined ( $P$. persimilis, $A$. californicus, O. strigicollis, and E. Formosa; Table 1). The corrected mortality ranged from 0 to $20.5 \%$ and, hence, fell in toxicity rating I of the IOBC.

\section{Discussion}

With the aim of developing a broad-based approach to controlling B. tabaci, a rational combination of several control measures, including selective chemical pesticides, natural enemies, ${ }^{30}$ ) virus-resistant or virus-tolerant varieties, ${ }^{31,32)}$ yellow sticky traps, ${ }^{33,34)}$ insect-proof screens, ${ }^{35)}$ and UV-controlling films ${ }^{36,37)}$ have been selectively used to keep pest density below acceptable economic loss levels in integrated pest management (IPM) strategies. To date, the principal control strategy in practice for several cultivated crops is treatment by the judicious use of selective insecticides, based on not only their mode of action but also their impact on natural enemies ${ }^{38)}$ and pollinators, ${ }^{38)}$ with
Table 1. Effect of acetylated glyceride treatment $(0.2 \%, \mathrm{v} / \mathrm{v})$ on the mortality of natural enemies

\begin{tabular}{|c|c|c|c|c|}
\hline Natural enemies & $\begin{array}{l}\text { Treatment } \\
\text { methods }\end{array}$ & Stages & $\begin{array}{l}\text { Day after } \\
\text { treatment }\end{array}$ & $\begin{array}{l}\text { Corrected } \\
\text { mortality }\end{array}$ \\
\hline \multirow{2}{*}{ Phytoseiulus persimilis } & \multirow{2}{*}{ Direct spray } & adult & 5 & 6.7 \\
\hline & & nymph & 5 & 15.9 \\
\hline \multirow{3}{*}{ Amblyseius californicus } & \multirow{3}{*}{ Direct spray } & adult & 5 & 7.9 \\
\hline & & nymph & 5 & 10.4 \\
\hline & & egg & 5 & 4.0 \\
\hline \multirow{4}{*}{ Orius strigicollis } & \multirow{3}{*}{ Direct spray } & adult & 5 & 3.4 \\
\hline & & nymph & 5 & 20.5 \\
\hline & & egg & 6 & 11.4 \\
\hline & Contact & adult & 5 & 12.9 \\
\hline \multirow{3}{*}{ Encarsia formosa } & \multirow{2}{*}{ Direct spray } & adult & 7 & 14.5 \\
\hline & & pupa & 15 & 9.1 \\
\hline & Contact & adult & 7 & 0 \\
\hline
\end{tabular}

Each treatment was applied with three replicates.

the aim of avoiding pest resurgence ${ }^{39)}$ and the development of cross-resistance. ${ }^{13)}$ Under these circumstances, natural products, including plant-derived oils and seed extracts, are growing in importance as alternative pest controls intended to be compatible with IPM strategies.

As first factors in practical use, natural products may not show sufficient control of target pests under practical conditions, partly because of their lower basic and residual activities, as well as lower systemic properties in comparison with chemical pesticides. For substances intended for practical control of B. tabaci, the optimization of both treatment frequency and concentration is very important for pest control. In our previous study of treatment frequency, acetylated glyceride $(0.2 \%, \mathrm{v} / \mathrm{v})$ treatment two or three times showed more residual activity on B. tabaci (Bbiotype) adults than did a single treatment, resulting in a large reduction of adults settling and nymphs remaining on eggplants in a plastic greenhouse test. ${ }^{40)}$ In the present study of treatment concentrations, the highest concentration of acetylated glyceride $(0.2 \%, \mathrm{v} / \mathrm{v})$ exhibited stronger repellency against B. tabaci (Bbiotype) adults as compared with lower concentrations $(0.125 \%$ and $0.1 \%, v / v)$ in both glass and plastic greenhouse tests. In addition, the number of settled adults and courting pairs of the Q-biotype of B. tabaci (Supplemental Tables S2 and S3) and T. vaporariorum adults (data not shown) were reduced by acetylated glyceride treatment, with the activity being as high as that against the B-biotype of B. tabaci.

In the next step toward practical use, treatment conditions that allow natural products to exert practical control on a target pest may lead to phytotoxicity on crops ${ }^{16,17,21)}$ and side effects on beneficial insects. ${ }^{41)}$ The acetylated glyceride treatment conditions defined here were commercially acceptable in terms of both tomato phytotoxicity and side effects on natural enemies. In addition, acute oral and contact toxicities of acetylated glyc- 
eride for the pollinator Apis mellifera (Hymenoptera, Apidae) (honeybee) were evaluated in accordance with EPPO Bulletin No. 170 (1992) and OECD, JMAFF, and EPA guidelines. There was no mortality at the upper limit of $100 \mu \mathrm{g} \mathrm{AI} / \mathrm{bee}$ in both a 48-hr contact test and a 48-hr oral test (data not shown).

Courting pair formation among adult whiteflies was significantly reduced with acetylated glyceride treatment. To the best of our knowledge, no mating disruption or courting disruption among B. tabaci adults on oil-treated leaves has been reported, although pheromone or pheromone analogs for a variety of insect species ${ }^{42-45)}$ for release over wide areas and sprayable microencapsulated sex pheromone formulation sprays ${ }^{46)}$ are available.

In conclusion, for best results, we recommend acetylated glyceride $(0.2 \%, \mathrm{v} / \mathrm{v})$ treatment two or three consecutive times at approximately 7-day intervals, when $B$. tabaci adults have not appeared or are at a low density in the greenhouse. Further study is necessary to assess the possibility of suppressing plant virus infections by repellent activity, and to evaluate the impact of courting disruption on the sex ratio of emerging adults of the second generation. Acetylated glyceride is now being registered as a novel repellent pesticide of whiteflies.

\section{Acknowledgements}

The authors would like to thank Saga University professors emeritus E. Kondo and S. Tojo for their constructive comments on the manuscript. We thank K. Honda at National Agriculture and Food Research Organization (NARO) for coordinating tests. We also thank H. Noguchi and K. Sashida of Riken Vitamin Co., Ltd. for technical information.

\section{References}

1) J. K. Brown, D. R. Frohlich and R. C. Rosell: Annu. Rev. Entomol. 40, 511-534 (1995).

2) I. Denholm, M. Cahill, T. J. Dennehy and A. R. Horowitz: Philos. Trans. R. Soc. Lond. B Biol. Sci. 353, 1757-1767 (1998).

3) L. A. Mound and S. H. Halsey (eds.): "Whitefly of the World. A Systematic Catalogue of the Aleyrodidae (Homoptera) with Host Plant and Nature Enemy Data," British Museum and John Wiley \& Sons, Chichester, 1978.

4) S. A. Hogenhout, E. D. Ammar, A. E. Whitfield and M. G. Redinbaugh: Annu. Rev. Phytopathol. 46, 327-359 (2008).

5) M. R. V. Oliveira, T. J. Henneberry and P. Anderson: Crop Prot. 20 709-723 (2001)

6) P. De la Rúa, B. Simón, D. Cifuentes, C. Martinez-Mora and J. L. Cenis: J. Zool. Syst. Evol. Res. 44, 25-33 (2006).

7) S. Ueda and J. K. Brown: Phytoparasitica 34, 405-411 (2006)

8) D. Chu, Y. J. Zhang, J. K. Brown, B. Cong, B. Y. Xu, Q. J. Wu and G. R. Zhu: Fla. Entomol. 89, 168-174 (2006).

9) L. P. Zhang, Y. J. Zhang, W. J. Zhang, Q. J. Wu, B. Y. Xu and D. Chu: J. Appl. Entomol. 129, 121-128 (2005).

10) L. M. Boykin, R. G. Shatters Jr., R. C. Rosell, C. L. McKenzie, R. A. Bagnall, P. De Barro and D. R. Frohlich: Mol. Phylogenet. Evol. 44, 1306-1319 (2007).

11) J. H. Martin, D. Mifsud and C. Rapisarda: Bull. Entomol. Res. 90, 407-448 (2000).

12) A. R. Horowitz, S. Kontsedalov, V. Khasdan and I. Ishaaya: Arch.
Insect Biochem. Physiol. 58, 216-225 (2005).

13) N. Prabhaker, S. J. Castle, T. J. Henneberry and N. C. Toscano: Bull. Entomol. Res. 95, 535-543 (2005).

14) G. D. Butler Jr., D. L. Coudriet and T. J. Henneberry: Southwest. Entomol. 13, 81-86 (1988).

15) G. D. Butler Jr., D. L. Coudriet and T. J. Henneberry: Southwest. Entomol. 14, 9-16 (1989).

16) G. D. Butler Jr. and T. J. Henneberry: Southwest. Entomol. 15, 123131 (1990).

17) G. D. Butler Jr. and T. J. Henneberry: Southwest. Entomol. 16, 63-72 (1991).

18) N. Prabhaker, N. C. Toscano and T. J. Henneberry: J. Econ. Entomol. 92, 40-46 (1999).

19) A. Fenigstein, M. Eliyahu, S. Gan-Mor and D. Veierov: Phytoparasitica 29, 197-206 (2001).

20) I. Aslan, H. Özbek, Ö. Çalmaşur and F. Şahïn: Ind. Crops Prod. 19, 167-173 (2004).

21) W. Zhang, H. J. McAuslane and D. J. Schuster: J. Econ. Entomol. 97, 1310-1318 (2004).

22) D. J. Schuster, S. Thompson, L. D. Ortega and J. E. Polston: J. Econ. Entomol. 102, 1482-1489 (2009).

23) N. W. Yang, A. L. Li, F. H. Wan, W. X. Liu and D. Johnson: Crop Prot. 29, 1200-1207 (2010).

24) S. I. Kim, S. H. Chae, H. S. Youn, S. H. Yeon and Y. J. Ahn: Pest Manag. Sci. 67, 1093-1099 (2011).

25) T. L. Moreau and M. B. Isman: Crop Prot. 34, 42-46 (2012).

26) M. S. J. Simmonds, J. D. Manlove, W. M. Blaney and B. P. S. Khambay: Entomol. Exp. Appl. 102, 39-47 (2002).

27) G. R. Camarillo, L. D. A. Ortega, M. A. C. Serrato and C. H. Rodriguez: Rev. Colomb. Entomol. 35, 177-184 (2009).

28) W. I. Choi, E. H. Lee, B. R. Choi, H. M. Park and Y. J. Ahn: J. Econ. Entomol. 96, 1479-1484 (2003).

29) S. A. Hassan, F. Bigler, H. Bogenshütz, E. Boller, J. Brun, J. N. M. Calis, J. Coremans-Pelseneer, C. Duso, A. Grove, U. Heimbach, et al.: Entomophaga 39, 107-119 (1994).

30) R. Gabarra, R. Zapata, C. Castañé, J. Riudavets and J. Arnó: IOBC WPRS Bull. 29, 71-76 (2006).

31) H. Toda, T. Yamamoto and K. Yamaguchi: Ann. Rept. Kansai Pl. Prot. 52, 65-67 (2010) (in Japanese).

32) A. Saito: Proc. Vege. Tea Sci. 3, 99-102 (2006) (in Japanese).

33) L. Yaobin, B. Yawei and Z. Jinming: J. Insect Sci. 12, 1-12 (2012).

34) D. Gerling and A. R. Horowitz: Ann. Entomol. Soc. Am. 77, 753-759 (1984).

35) M. J. Berlinger, R. A. J. Taylor, S. Lebiush-Mordechi, S. Shalhevet and I. Spharim: Bull. Entomol. Res. 92, 367-373 (2002).

36) Y. Antignus, M. Lapidot, D. Hadar, Y. Messika and S. Cohen: J. Econ. Entomol. 91, 1401-1405 (1998).

37) Y. Antignus, N. Mor, R. Ben-Joseph, M. Lapidot and S. Cohen: Environ. Entomol. 25, 919-924 (1996).

38) N. Desneux, A. Decourtye and J. M. Delpuech: Annu. Rev. Entomol. 52, 81-106 (2007).

39) G. J. Devine, I. Ishaaya, A. R. Horowitz and I. Denholm: Crop Prot. 17, 717-726 (1998)

40) Y. Arimoto and T. Kashima: IPPC Proceeding, 90-93 (2007).

41) A. Beattie, D. Watson, M. Stevens, D. Rae and R. Spooner-Hart (eds.): "Spray Oils Beyond, Sustainable Pest and Disease Management," University of Western Sydney, Australia, 2000.

42) R. T. Cardé and A. K. Minks: Annu. Rev. Entomol. 40, 559-585 (1995).

43) A. M. Koppenhöfer, S. Polavarapu, E. M. Fuzy, A. Zhang, K. Ketner and T. Larsen: Environ. Entomol. 34, 1408-1417 (2005). 
44) S. Polavarapu, M. Wicki, K. Vogel, G. Lonergan and K. Nielsen: Environ. Entomol. 31, 1268-1275 (2002).

45) V. M. Walton, K. M. Daane, W. J. Bentley, J. G. Millar, T. E. Larsen and R. Malakar-Kuenen: J. Econ. Entomol. 99, 1280-1290 (2006).

46) A. L. Il'ichev, L. L. Stelinski, D. G. Williams and L. J. Gut: J. Econ. Entomol. 99, 2048-2054 (2006). 